\title{
"A Paradox Persists When the Paradigm Is Wrong": Pisacano Scholars' Reflections from the Inaugural Starfield Summit
}

\author{
Noemi Doohan, MD, PhD, Anastasia J. Coutinho, MD, MHS, Jennifer Lochner, MD, \\ Diana Wobler, MD, and Jennifer DeVoe, MD, DPhil
}

The inaugural Starfield Summit was hosted in April 2016 by the Robert Graham Center for Policy Studies in Family Medicine and Primary Care with additional partners and sponsors, including the Pisacano Leadership Foundation (PLF). The Summit addressed critical topics in primary care and health care delivery, including payment, measurement, and team-based care. Invited participants included an interdisciplinary group of pediatricians, family physicians, internists, behaviorists, trainees, researchers, and advocates. Among the family physicians invited were both current and past PLF (Pisacano) scholars. After the Summit, a small group of current and past Pisacano scholars formed a writing group to reflect on and summarize key lessons and conclusions from the Summit. A Summit participant's statement, "a paradox persists when the paradigm is wrong," became a repeated theme regarding the paradox of primary care within the context of the health care system in the United States. The Summit energized participants to renew their commitment to Dr. Starfield's 4 C's of Primary Care (first contact access, continuity, comprehensiveness, and care coordination) and to the Quadruple Aim (quality, value, and patient and physician satisfaction) and to continue to explore how primary care can best shape the future of the nation's health care system. (J Am Board Fam Med 2016;29:793-804.)

Keywords: Family Practice; Forecasting; Leadership; Personal Satisfaction; Physicians, Family; Primary Health Care; Research Personnel; Writing

Amid cherry blossoms in Washington DC (April 23 to 26, 2016), 146 invited primary care experts and advocates gathered in honor of one of the greatest researchers in primary care-Barbara Starfield. The inaugural Starfield Summit was hosted and organized by the Robert Graham Center for Policy

This article was externally peer reviewed.

Submitted 16 July 2016; revised 26 August 2016; accepted 6 September 2016.

From the Department of Family and Community Medicine, University of California-Davis (ND) (past Pisacano scholar); Santa Rosa Family Medicine Residency, Santa Rosa, California (AJC) (current Pisacano scholar); Department of Family Medicine and Community Health, University of Wisconsin-Madison (JL) (past Pisacano scholar); Brown Family Medicine Residency, Providence, Rhode Island (DW) (current Pisacano scholar); Department of Family Medicine, Oregon Health \& Science University, Portland (JD) (past Pisacano scholar)

Funding: none.

Conflict of interest: none declared.

Corresponding author: Noemi Doohan, MD, PhD, Ukiah Valley Medical Center, 275 Hospital Drive, Ukiah, CA 95482 (Noemi.doohan@ah.org).
Studies in Family Medicine and Primary Care and cosponsored by the American Board of Family Medicine Foundation, the Pisacano Leadership Foundation (PLF), and Family Medicine for America's Health. The website (www.starfieldsummit. com) hosts detailed information and resources from the Summit, including the list of attendees and speakers. The Summit aimed to focus discussion on critical topics in primary care and health care delivery, including payment, measurement, and teambased care. Invited participants included an interdisciplinary group of pediatricians, family physicians, internists, behaviorists, trainees, researchers, and advocates. Among the family physicians invited were both current and past PLF (Pisacano) scholars.

\section{Summit Structure and Discussion Process}

The invited speakers presented 20-minute "Big Idea" presentations (in the style of TED Talks ${ }^{1}$ ) discussing each of 3 featured topic domains (pay- 
ment, measurement, and team-based care), which were followed by small-group breakout sessions (fashioned after the World Café method ${ }^{2}$ ). The break-out sessions were structured into 4 predetermined interprofessional discussion groups that remained constant throughout the entire conference.

Speakers, matched with 2 colleagues assigned to assist in framing and leading discussion in these groups, rotated among the 4 discussion groups. During discussions, written notes were taken by Pisacano scholars and are being used to create the content for multiple dissemination reports, including this Article. The Summit culminated with a Congressional Forum in the US Capitol Visitor's Center. ${ }^{3}$ Summit attendees paid their own way to the event; in some cases, individuals received full or partial sponsorship from their supporting organizations.

Appendix 1 lists the Summit attendees and includes asterisks next to the names of the Pisacano Scholars who acted as note-takers during the break-out sessions. The described format for discussion allowed themes to develop within groups, which were shared at multiple levels throughout the Summit. This historic Summit garnered a high level of expertise, energy, and enthusiasm for primary care and inspired conversations regarding primary care's role in health care systems-past, present, and future. Based on the success of this first Summit, future Starfield Summits are being planned.

\section{PLF and Its Role in the Summit}

The PLF, created by the American Board of Family Medicine in 1991 to identify and develop leaders in family medicine, awards the Pisacano Scholarship to a small group of medical student leaders entering the discipline of family medicine each year. In addition to scholarship funding provided to current scholars throughout their residency training, current and past (alumni) Scholars have the opportunity to participate in an annual leadership symposium. In 2016, the PLF held its annual symposium as a preconference to the inaugural Starfield Summit, bringing together a diverse group of Pisacano scholars and alumni, including policy leaders, academics, practicing physicians, and family medicine trainees. Eighteen current Pisacano Scholars and 21 Pisacano Scholar alumni attended the Starfield Summit, which had 146 total invited attendees. Following the Pisacano symposium and the Star- field Summit, the authors formed a writing group to summarize highlights from the Summit and to contribute to ongoing conversations around the future of primary care in the United States.

\section{Overview of the Summit Discussions: "A Paradox Persists When the Paradigm is Wrong"}

During the pre-Summit PLF symposium, Pisacano scholars and alumni were introduced to the Starfield Summit topics to prepare for discussion about the state of primary care in the United States. In response, Pisacano Scholar Dr. Justin Mutter remarked, "a paradox persists when the paradigm is wrong." This comment became a theme repeated throughout the Summit, given that we considered the paradox of primary care within the context of our current health care system.

\section{What is the Paradox?}

Primary care is better at improving the health of the forest than of the trees. Dr. Kurt Stange explored this paradox and summarized numerous studies illustrating that when primary care teams are measured by care for individual diseases, primary care performance is inferior to specialty care with regard to disease-specific outcomes and adherence to disease-specific guidelines and recommendations. ${ }^{4}$ However, in ecological studies, improved population health outcomes are associated with a larger, stronger, and more integrated primary care system. ${ }^{4,5}$

The Starfield Summit explored several additional paradoxes relevant to primary care. Although the United States spends more on health care than other high-income countries, we have poorer health outcomes. ${ }^{5}$ These outcomes are thought to have been driven by a historic lack of commitment to social services and primary care. ${ }^{6}$ In the United States, clinical care is responsible for only $14 \%$ of health status ${ }^{7,8}$, but accounts for $95 \%$ of US health care costs. ${ }^{9}$ Furthermore, the United States is the only high-income country without a publicly funded universal health system ${ }^{6}$ and $9 \%$ of Americans remain without insurance. ${ }^{10}$

\section{What is the Paradigm?}

In our current system, fee-for-service reimbursement and productivity models reward the administration of tests, procedures, and medications aimed at treating individual diseases, ${ }^{11}$ with minimal reimbursement for coordinated services that consider 
the whole patient in the context of their community. This disease-centered paradigm creates vertical medical silos focusing on specific organ systems and illnesses. Without an incentive for holistic treatment and without measures for comprehensive care, integration across care domains is often not prioritized. Further, a critical aspect of health care delivery-the relationship between provider and patient-has been devalued, as evidenced by shorter primary care visits and inconsistent reimbursement for care coordination and asynchronous care services (eg, phone calls, emails), ${ }^{12-14}$ which are capable of strengthening connections and increasing "touches" between patients and primary care teams. Current systems of care are fragmented, force patients to choose specific in-network providers, and provide few resources for delivering preventive health care services or addressing the social determinants of health. ${ }^{15}$ Without a radical shift in care delivery and payment to adequately address the upstream causes of illness, sustainability of preventive services and coordinated chronic disease management is threatened. Continuation of the current paradigm will lead to escalation of health care costs without the assurance of improved actual health of individuals and of populations.

\section{Is a Paradigm Shift on the Horizon?}

In a ground-breaking decision to move the United States away from fee-for-service reimbursement and toward value-based payment, Congress passed the Medicare Access \& CHIP Reauthorization Act (MACRA) in April 2015. MACRA attempts to alter the way in which Medicare will pay for services, including ending the sustainable growth rate formula for how Medicare payments were previously determined, creating a new framework for paying health care providers for comprehensive care, and establishing new quality metrics. ${ }^{16}$ Although this new system shows promise, specific details about these payment mechanisms and quality reporting have yet to be released. Without established standards, MACRA leaves primary care leaders wondering how value-based payments will change health care delivery. Will the current measurement and delivery infrastructures remain or will valuebased payments encourage and incentivize innovative delivery models? Will primary care's emphasis on whole-person wellness and population health be adequately valued or is the paradigm shifting only incrementally from fee-for-(individual) service to fee-for-(individual) measurement? Will the financial viability and, thus, the long-term survival of primary care become more certain or will it continue to be threatened? Can our health care system reach a place where a healthier forest equates to healthier trees?

\section{What Would Be a True Paradigm Shift?}

The 2016 Starfield Summit created an opportunity to examine primary care bright spots, disruptive innovations, policy-relevant issues, and research priorities. New primary care ideas arose and old ideas re-emerged. Participants envisioned a new US health care system in which the strengths of both primary and specialty care could be combined with public and behavioral health to emphasize better quality of care, greater whole-person wellbeing, improved population health outcomes, and improved physician satisfaction. Together we envisioned a paradigm shift in which a redesigned system of delivery, payment, and measurement could energize the primary care workforce and create a structure for improved health outcomes for the individuals and populations of our nation. The 3 tables included list "brainstorming themes" that emerged from the discussion of each of the 3 featured topic domains (payment, measurement, and team-based care) and include representative statements from these discussions.

\section{Summarizing the Summit: Facts, Discussion Themes, and Authors' Thoughts \\ 1) Payment: Breaking Down Vertical Silos of Care, Creating Global Budgets}

Although the Summit could not define a scalable payment model for the entire US health care system and the primary care function, several themes regarding important elements of an effective payment system arose in Summit discussions and are summarized in Table 1. Several presenters highlighted the limitations of our current payment structures and the need for broader support of primary care services. Systems of payment based on fee-for-service reimbursement favor procedures and specialists, driving health care into vertical medical silos and promoting volume of services over value. This trajectory inhibits the improvement of primary care and the financial sustainability of the health care system. ${ }^{11,17}$ Despite inherent 
Table 1. Brainstorming Themes Regarding Payment Discussed at the 2016 Starfield Summit

Themes of Starfield Summit Participants' Discussion on Payment

Representative Statements Reflecting Theme

There is currently no streamlined, organized system of payment for healthcare.

Barriers and silos hamper innovative payment models.

Payment models must support, and be supported by, appropriate data measurement, data collection, and delivery infrastructure.

Effective payment for primary care would pay for accessibility, comprehensiveness, continuity, and coordination.

Payment needs to be flexible so that clinics, teams, and health systems can use global payments to meet patients in innovative ways and address population health.

An effective payment system needs to be risk-adjusted on the population level, rather than individual patients.

Budgets for primary care need to include interventions that address the social determinants of health.

- Working with eighty different payers is difficult on a practice.

- Different payment models serve to fragment our work by turning each aspect of healthcare into a separate transaction.

- The problem of a reductionist, disease-centered paradigm affects specialties as well as primary care.

- We need to redefine the buckets of how we pay for social services and healthcare, with no walls between the issues that drive health, including upstream causes.

- It is hard to innovate within regulatory environments that narrowly define healthcare.

- How do we know when primary care is doing a good job?

- We need good evidence on what makes a difference for the health of patients and populations.

- We need payment models that support implementation of new effective services.

- Payment needs to honor the patient-provider relationship...and be structured around ways providers can be held accountable.

- How we define primary care is currently the sum of our fee-for-service diagnosis codes.

- Primary care needs to take accountability for population health and advocate for a payment system that reflects this.

- The population health aspect of the triple aim lies almost entirely outside of the health system as it currently exists.

- Mandated investments in primary care in Rhode Island shows you can bend the cost curve with a global permember-per-month flexible payment on a large scale.

- Risk adjustment is necessary to prevent further marginalization of vulnerable populations.

- Social determinants of health are not just things that poor people face, they are a problem for everyone.

- Why is there not time for pro-active case management by clinicians?

- Need to address all the things that our patient's struggle with to create health.

problems in the fee-for-service model, it can be valuable if restructured to place higher fees on services that support improvement in overall health outcomes rather than individual disease states and when used for low-cost and underutilized services such as vaccines. ${ }^{11}$ Alternative models that incorporate different payment schemes are being implemented across the country. Summit participants discussed advantages and disadvantages of these models and how some experiments show promise for the future. For example, the state of Maryland created global budgets in which hospitals partnered with the Centers for Medicare and Medicaid Services to abolish fee-for-service payments and re- place them with a global funding structure, creating the first hospital risk-adjusted rate regulation system. ${ }^{18}$ This transformed payment model allows hospitals to focus on outcomes and value while maintaining financial stability. In the first year alone, Maryland saved Medicare \$116 million while reducing the rate of potentially preventable conditions by $26.3 \% .{ }^{19}$ In Rhode Island, a policy change created a mandated increase in primary care expenditures to $10 \%$ of total health care expenditures, leading to a savings of over $\$ 100$ million in its first 4 years. ${ }^{20}$ Rather than simply increasing fee-forservice rates for primary care services, payers were required to instead invest in other primary care 
resources such as care management, behavioral health services, and increased health information exchange. Summit participants also learned about a disruptive payment innovation, Direct Primary Care (DPC), and about how DPC organizations such as Qliance, Iora Health, and One Medical Group are changing the traditional paradigm through per-member payment models that allow flexibility in service delivery. ${ }^{21-24}$ These new payment paradigms require clinical leaders, employers, and patients to come together in unique ways. MACRA may also help to shift these payment paradigms, but it is too soon to predict whether it will inspire the radical change needed for transformation.

Innovations in financing and delivery of health care provide hope and direction for the future, but many questions remain. Which of these payment and delivery models will work to provide the best health outcomes and will be scalable on a national level? Perhaps the best answers will emerge, as in Maryland and Rhode Island, by turning to individual states for solutions that will create a healthier America. To determine which of these payment systems has the most potential, we must begin to create metrics that capture outputs relevant to primary care.

\section{2) Measurement: Are We Measuring What Matters Most?}

Summit discussions around pay-for-performance included some positive comments regarding its value in individual disease-based evaluation and reimbursement, while drawing attention to important limitations. It remains unclear how to measure components of care delivery that influence broader health outcomes, especially in complex patients. Table 2 summarizes themes that emerged from the Summit discussions regarding the quality metrics that can be used, or need to be developed, to assess the ability of primary care to change health outcomes and improve population health.

A variety of Summit talks explored what we know about measuring the primary care function.

Currently $\$ 15.4$ billion is spent annually on monitoring quality. ${ }^{25}$ Professor Amanda Howe, an academic general practitioner from the United Kingdom (UK) and the incoming president of the World Organization of Family Doctors (Wonca), shared a cautionary tale of how an initiative to measure and reward primary care quality across the
UK (the Quality Outcomes Framework [QOF]) did not have the consequences it intended. ${ }^{26}$ The QOF attempted to provide value-based payments to physicians, but its multiple disease-based metrics supported process driven rather than outcomes-based care. Over time it tended to fragment the way primary health care was delivered, rather than improving whole-person or population care. This contributed to a decline in physician satisfaction with the QOF, and there was no overall measurable improvement in health inequities. ${ }^{26}$

Measuring clinics on their ability to maintain optimal access and a comprehensive array of services are 2 examples of ways in which metrics can support some of the features of primary care that are thought to underlie the value it brings to patients and health systems. ${ }^{27,28}$ Another aspect of primary care that is difficult to measure, but arguably the most personally meaningful, is the effect of a therapeutic relationship with a consistent clinician. ${ }^{13,14}$ Although not all aspects of clinical practice can be measured, metric reform has the potential to truly transform primary care delivery.

Quality metrics and subsequent payments that incentivize and support the primary care function have the potential to affect individual and population health. However, radically shifting the current measurement paradigm presents challenges including the difficult tasks of development, implementation, and evaluation of metrics that lead to improved outcomes and are relevant to patients. In addition to capturing important primary care functions, measurement needs to account for social vulnerabilities so that quality can be evaluated in the context of the social determinants of health and health disparities.

\section{3) Team-Based Care: Revisiting and Revitalizing Old Models}

Summit discussions yielded consensus that teams are critical for the success of the primary care function. Table 3 reflects themes that came out of the varied discussions on the topics of teams. Summit participants examined roadmaps for transforming primary care practices with team-based approaches. Examples highlighted included the 10 Building Blocks of High-Performing Primary Care, ${ }^{29}$ team strategies for integrating behavioral health and primary care ${ }^{30}$ incorporating patients and communi- 
Themes of Starfield Summit Participants' Discussion on

Measurement

Representative Statements Reflecting Theme

Measurement must reflect characteristics of health systems we know are related to improved population health, including accessibility, comprehensiveness, continuity, and coordination.

Indicators of quality care must reflect various patient populations and individual patients' goals.

Measurement leads to fatigue and burnout and thus, lack of innovation.

Measurement needs to shift towards care coordination and team care, as one physician or one clinical practice is not responsible for health outcomes.

Measurement needs to account for social determinants of health, as only $10 \%$ to $20 \%$ of individual health is related to clinical care.

Measurement systems are too complicated.

Measurement and payment need to be reformed together.

The current measurement system does not measure value.

Measurement should focus on trends, not a point in time.
- What really matters is the unmeasurable...We must measure trust, communication, relationships, openness ... These are what correlates with outcomes.

- Measures don't capture the range of what I do in my daily practice.

- What are the priorities of my patients?

- How can we bring in the patient's voice?

- Patient preferences and quality of life change over time; how do we reflect that?

- If our system was not so prescriptive, it would allow individuals and organizations to develop their own solutions.

- We rely too much on clinician incentives and undervalue intrinsic motivation.

- Break down the silos between primary care and specialties.

- Measurements are disproportionately focused on certain providers-disease-specific measures do not capture primary care, but similarly, radiologists do not get measured on patient outcomes.

- Patient outcomes and patient panels are measuring the wrong issue because people with the worst problems don't come in for care-therefore, we need to have community-based measurement.

- How do we create measures to account for community issues that neither patients nor providers can control-like transportation, access, employment?

- Simplify the verbiage.

- Too much reporting burden.

- All payers should be using the same system.

- We can't really talk about population health outcomes without universal access.

- Value is hard to define...and it is different for every provider and every patient.

- Does measurement produce the product we want and need? Does it measure health or quality of life and care?

- Do we really need to have incentives? The system is set up in the wrong way for us to deliver care we believe in.

- We need more long-term measures-not the first avoidable readmission, but the number of re-admissions over a year or over five years.

- There's so much devil in the details, no one gets it right the first time. ties into primary care teams (eg, community health workers),${ }^{31}$ and approaches for increasing joy in practice. $^{32}$ Participants concluded that effective teams must be adaptable with regard to the needs of the population, size of the community, and specific roles of team members. ${ }^{3-35}$ The patient as a vital team member must remain at the center of all team activities. Team-based care must also exist across specialties and locations of the health system (eg, clinic, emergency department, hospital), and community engagement as a form of team care is crucial.
Team-based care can improve access to a broad scope of primary care for individuals and communities. For example, team members can share routine well-care and preventive care tasks (eg, referrals for cancer screenings, immunization forecasting) as well as care coordination and education, enabling clinicians to see fewer, but more complex, patients per day for longer visits and freeing time for additional leadership and administrative tasks. ${ }^{36-40}$ Although team-based approaches have improved efficiency and quality in many studies $^{41}$, they have shown limited effect on addressing 
Themes of Starfield Summit Participants' Discussion on TeamBased Care

Good teams require the integration of primary care with services outside the structure of the traditional primary care clinic.

Team-based care can act as a catalyst to joyful practice, but will require upfront and continuous investment to function successfully.

Team-based care can increase the comprehensiveness of services available and are more likely to meet patients' needs.

Specialists should be valued members of teams and our system should promote communication between specialties and primary care.

Creating excellent teams starts with having the right people in medical school-those who can be excellent team members-and how we train them to be those members.

Changing current practices to achieve team-based care will be difficult.

The patient needs to be a part of the team in team-based care.
Representative Statements Reflecting Themes

- We need Accountable Health Communities instead of Accountable Care Organizations.

- We need to include community health workers and public health professionals to help address the social determinants of health.

- We inadvertently stigmatize mental health issues every time we refer out of clinic.

- We need to "Share the Care" with team members.

- Teams can help prevent the death spiral of primary care via burnout

- Team hygiene is critical: this requires coaching/leadership training.

- Teams are the antidote to the trend towards narrowing scope of practice within primary care.

- Teams can facilitate communication with specialists and supportive services to improve comprehensive patient care.

- We ignore a large part of our health community when we don't partner with specialist colleagues.

- Everything is about relationships and teams promote those stronger relationships.

- We need to match the micro-culture of teams with the macro-culture of institutions.

- We must stop training dehumanized cowboys.

- We need to find and train individuals with substrate to be hybrids-the technologist and the humanist.

- Where is the "UpToDate" for practice change?

- Research is not enough to drive change. We need partnerships and alliances to fuel action.

- Start each team meeting with a patient story.

- We need to get out of the "safe" environment of our clinics and into the community to build partnerships with our patients.

- We need to partner with patients for practice redesign-they have unprecedented power to advocate with us.

- We need patient advocates with "lived experiences" to be on clinic boards and contribute to the betterment of the clinic and of the community. social determinants of health and connecting patients with specialty care. ${ }^{42}$

Sidney and Emily Kark, the founders of community-oriented primary care, incorporated community needs assessments, population health data, community health workers, and multi-disciplinary teams using community-oriented, team-based approaches in the rural South African Pholela Health Centre during the 1940s. ${ }^{43}$ As the paradigm continues to shift away from volume-based care and toward teams, we should revisit these and other pioneering models of integrated primary care, public health, and behavioral health. Patient-Centered Medical Homes with patient navigators, health coaches, integrated behavioral health, and daily huddles are also reemerging as a path to improved care. ${ }^{44}$

\section{Discussion}

The Starfield Summit renewed our commitment to Dr. Starfield's 4 C's of Primary Care (first contact access, continuity, comprehensiveness, and care coordination) $^{45}$ and to the Quadruple Aim (quality, value, and patient and physician satisfaction). ${ }^{46}$ If the current payment paradigm persists, our health care system will continue to be dominated by competition and profit instead of collaboration on behalf of our patients and communities. We must 
move to a payment system accountable for improved health outcomes with careful attention to social and clinical vulnerabilities to ensure that health disparities narrow, not widen. These outcomes must include evidence-based, whole personcentered, comprehensive metrics in addition to those that are disease centered. This will require the development, implementation, and evaluation of methods for measuring the outcomes that matter most in primary care and population health. Models of team-based care must be reinvigorated and reinvented in today's world.

\section{Importance of Primary Care Research}

The teachings and research of Dr. Starfield are both reassuring and inspiring as we continue along this path to radically shifting entrenched paradigms. Starfield's rigorous work throughout the world illustrated how strong primary care foundations contribute to better health for populations at lower costs. ${ }^{5,47}$ Her work also demonstrated the need for sustained infrastructure to support primary care and health systems delivery researchinfrastructure that supports our best and brightest scientists and infrastructure that facilitates future innovation and discovery that can be scaled to serve populations. $^{48,49}$ By building and strengthening $21^{\text {st }}$ century primary care laboratories, we can rigorously evaluate innovative care models and expanded primary care financing and delivery systems. ${ }^{49}$ As evidence mounts, it can inform better policies and accelerate the transformation of primary care and the health system as a whole. A central premise of the Starfield Summit, which needs to be tested, is that positive change in health care will occur when researchers, policy makers, and clinicians work together to design and execute high-quality primary care research, and implement and disseminate the resulting best practices.

\section{Conclusion}

Now is a time of opportunity to build on the foundational evidence created by Dr. Starfield, deepening our discoveries of how primary care can most optimally affect the future of health and health care delivery in this country Following in Dr. Starfield's footsteps and standing on the shoulders of primary care giants, we will courageously continue to study, learn, practice, and shift the paradigm until the paradox fails to exist.
The authors gratefully acknowledge formatting assistance from Sonja Likumahuwa-Ackman and Rebecca Luoh of Oregon Health Sciences University Family Medicine department.

\section{References}

1. TED: Ideas worth spreading. Available from: http:// www.ted.com/. Accessed August 17, 2016.

2. The World Cafe. Available from: http://www. theworldcafe.com/. Accessed August 17, 2016.

3. Starfield Summit Schedule. Available from: http:// www.starfieldsummit.com/schedule/. Accessed June 29, 2016.

4. Stange KC, Ferrer RL. The paradox of primary care. Ann Fam Med 2009;7:293-9.

5. Macinko J, Starfield B, Shi L. The contribution of primary care systems to health outcomes within Organization for Economic Cooperation and Development (OECD) countries, 1970-1998. Health Serv Res 2003;38:831-65.

6. Squires D, Anderson C. U.S. health care from a global perspective: spending, use of services, prices, and health in 13 countries. Commonwealth fund. Available from: http://www.commonwealthfund. org/publications/issue-briefs/2015/oct/us-health-carefrom-a-global-perspective. Published October 2015. Accessed June 29, 2016.

7. Centers for Medicare and Medicaid Services, Office of the Actuary. National Health Expenditures, by Source of Funds and Type of Expenditure: Calendar Years 1994-1998. 2000.

8. Centers for Disease Control (CDC). Estimated national spending on prevention-United States, 1988. MMWR Morb Mortal Wkly Rep 1992;41:529-31.

9. McGinnis JM, Foege WH. Actual causes of death in the United States. JAMA 1993;270:2207-12.

10. (ASPA) AS for PA. 20 million people have gained health insurance coverage because of the Affordable Care Act, new estimates show. Available from: HHS.gov. http://www.hhs.gov/about/news/2016/ 03/03/20-million-people-have-gained-healthinsurance-coverage-because-affordable-care-actnew-estimates. Published March 3, 2016. Accessed June 29, 2016.

11. Miller HD. From volume to value: Better ways to pay for health care. Health Aff Proj Hope 2009;28: 1418-28.

12. Dickson V. Doctors are leaving federal dollars for coordinated care on the table. Modern healthcare. Available from: http://www.modernhealthcare.com/ article/20151013/NEWS/151019975. Published October 13, 2015. Accessed July 6, 2016.

13. Colwill JM, Frey JJ, Baird MA, Kirk JW, Rosser WW. Patient relationships and the personal physician in tomorrow's health system: A perspective from the Keystone IV conference. J Am Board Fam Med 2016;29 Suppl 1(Suppl 1):S54-S59.

14. Green LA, Puffer JC. Reimagining our relationships 
with patients: A perspective from the Keystone IV conference. J Am Board Fam Med 2016;29 Suppl 1(Suppl 1):S1-S11.

15. DeVoe JE, Bazemore AW, Cottrell EK, et al. Perspectives in primary care: A Conceptual framework and path for integrating social determinants of health into primary care practice. Ann Fam Med 2016;14:104-8.

16. Centers for Medicare and Medicaid Services. The merit-based incentive payment system (MIPS) and alternative payment models (APMs). Quality payment program: Delivery system reform, medicare payment reform, \& MACRA. Available from: https://www.cms.gov/Medicare/Quality-InitiativesPatient-Assessment-Instruments/Value-BasedPrograms/MACRA-MIPS-and-APMs/MACRAMIPS-and-APMs.html. Published May 9, 2016. Accessed June 29, 2016.

17. DeVoe JE, Stenger R. Aligning provider incentives to improve primary healthcare delivery in the United States. O A Fam Med 2013;1:1-7.

18. Centers for Medicare and Medicaid Services. Maryland all-payer model. Available from: https:// innovation.cms.gov/initiatives/Maryland-All-PayerModel/. Published February 6, 2015. Accessed June 29, 2016.

19. Patel A, Rajkumar R, Colmers JM, Kinzer D, Conway PH, Sharfstein JM. Maryland's global hospital budgets-Preliminary results from an all-payer model. N Engl J Med 2015;373:1899-901.

20. Koller CF, Brennan TA, Bailit MH. Rhode Island's novel experiment to rebuild primary care from the insurance side. Health Aff Milwood 2010;29:941-7.

21. Von Drehle D. Medicine is about to get personal. Time December 2014.

22. Eskew PM, Klink K. Direct primary care: Practice distribution and cost across the nation. J Am Board Fam Med 2015;28:793-801.

23. Fernandopulle, Rushika. Breaking the fee-for-service addiction: Let's move to a comprehensive primary care payment model. Health Affairs Blog. Available from: http://healthaffairs.org/blog/2015/ 08/17/breaking-the-fee-for-service-addiction-letsmove-to-a-comprehensive-primary-care-paymentmodel/. Published August 17, 2015. Accessed June 29, 2016.

24. Mac R. One medical group: A concierge service by another name (and price). Forbes. Available from: http://www.forbes.com/sites/ryanmac/2013/03/27/ one-medical-group-a-concierge-service-by-anothername-and-price/. Published March 17, 2013. Accessed June 29, 2016.

25. Casalino LP, Gans D, Weber R, et al. US physician practices spend more than $\$ 15.4$ billion annually to report quality measures. Health Aff Proj Hope 2016; 35:401-6.

26. Howe A. Policy bite: Can you measure quality?
WONCA. Available from: http://globalfamilydoctor. com/News/PolicyBitecanyoumeasurequality.aspx. Published May 2016. Accessed June 29, 2016.

27. Bazemore A, Petterson S, Peterson LE, Phillips RL. More comprehensive care among family physicians is associated with lower costs and fewer hospitalizations. Ann Fam Med 2015;13:206-13.

28. Lowe RA, Localio AR, Schwarz DF, et al. Association between primary care practice characteristics and emergency department use in a medicaid managed care organization. Med Care 2005;43:792-800.

29. Bodenheimer T, Ghorob A, Willard-Grace R, Grumbach K. The 10 building blocks of high-performing primary care. Ann Fam Med 2014;12:166-71.

30. Green LA, Cifuentes M. Advancing care together by integrating primary care and behavioral health. J Am Board Fam Med 2015;28 Suppl 1(Suppl 1):S1-S6.

31. Kaufman A, Powell W, Alfero C, et al. Health Extension in New Mexico: An Academic Health Center and the Social Determinants of Disease. Ann Fam Med 2010;8:73-81.

32. Sinsky CA, Willard-Grace R, Schutzbank AM, Sinsky TA, Margolius D, Bodenheimer T. In Search of Joy in Practice: A Report of 23 High-Functioning Primary Care Practices. Ann Fam Med 2013;11:272-8.

33. Bazemore A, Wingrove P, Peterson L, Petterson S. The diversity of providers on the fam med team. J Am Board Fam Med 2016;29:8-9.

34. Peikes DN, Reid RJ, Day TJ, et al. Staffing patterns of primary care practices in the comprehensive primary care initiative. Ann Fam Med 2014;12:142-9.

35. Ku L, Frogner B, Steinmetz E, Pittman P. Many paths to primary care: flexible staffing and productivity in community health centers. Washington, D.C: The George Washington Health Workforce Research Center; 2014;1-5.

36. Wagner EH. The role of patient care teams in chronic disease management. BMJ 2000;320(7234): 569-72.

37. Ghorob A, Bodenheimer T. Share the Care ${ }^{\mathrm{TM}}$ : Building teams in primary care practices. J Am Board Fam Med 2012;25:143-5.

38. Ghorob A, Bodenheimer T. Sharing the care to improve access to primary care. N Engl J Med 2012; 366:1955-7.

39. Saba GW, Villela TJ, Chen E, Hammer H, Bodenheimer T. The myth of the lone physician: Toward a collaborative alternative. Ann Fam Med 2012;10: 169-73.

40. DeVoe JE, Barnes K, Morris C, et al. The personal doctoring manifesto: A perspective from the Keystone IV conference. J Am Board Fam Med 29 Suppl 1:S64-S68.

41. Gallo JJ, Zubritsky C, Maxwell J, et al. Primary care clinicians evaluate integrated and referral models of behavioral health care for older adults: Results from a multisite effectiveness trial (PRISM-E). Ann Fam Med 2004;2:305-9. 
42. Taylor EF, Lake T, Nysenbaum J, Peterson G, Meyers D. Coordinating Care in the Medical Neighborhood: Critical Components and Available Mechanisms. Mathematica Policy Research and AHRQ; 2011. Available from: https://pcmh.ahrq.gov/sites/default/files/ attachments/Coordinating\%20Care \%20in \% 20the \% 20Medical\%20Neighborhood.pdf. Accessed June 29, 2016.

43. Geiger HJ. Community-oriented primary care: The legacy of Sidney Kark. Am J Public Health 1993;83: 946-7.

44. Mitchell P, Wynia M, Golden R, et al. Core Principles \& Values of Effective Team-Based Health Care. Washington, D.C.: Institute of Medicine; 2012.
45. Starfield B. Primary Care: Concept, Evaluation, and Policy. Oxford University Press, USA; 1992.

46. Bodenheimer T, Sinsky C. From triple to quadruple aim: Care of the patient requires care of the provider. Ann Fam Med 2014;12:573-6.

47. Starfield B, Shi L, Macinko J. Contribution of primary care to health systems and health. Milbank Q 2005;83:457-502.

48. deGruy FV 3rd, Ewigman B, DeVoe JE, et al. A plan for useful and timely fam med and primary care research. Fam Med 2015;47:636-42.

49. DeVoe JE, Likumahuwa-Ackman S, Shannon J, Steiner-Hayward E. Creating 21st century laboratories and classrooms for improving population health. Acad Med Press 2016 [Epub ahead of print]. 


\section{Appendix 1}

List of Attendees at Starfield Summit (from http://

www.starfieldsummit.com/documents/)

*Indicates Pisacano Scholar notetaker

Larry Anderson

Bengt Arnetz

*Kathleen Barnes

Andrew Bazemore

Darcy Benedict

${ }^{*}$ Paige Bennett

Robert Berenson

Arlene Bierman

Mary Beth Bigley

Jonathan Blum

Elizabeth Brown

Shannon Brownlee

Jennifer Carroll

Bob Cattoi

Agnes Cawi

Steve Cha

Candice Chen

Frederick Chen

*Maggie Chen

Marshall Chin

Megan Coffman

Jonathan Cohn

Steve Cook

*Anastasia Coutinho

Ardis Davis

Jennifer Devoe

*Trevor Dickey

Perry Dickinson

Noemi Doohan

Robert Dribbon

Marguarite Duane

Elizabeth Enschede

Kim Epperson

Rebecca Etz

Bernard Ewigman

Blake Fagan

Rushika Fernandopulle

*Jillian Fickenscher

Terry Findlay

Michael Fine

Anne Gaglioti

Nicole Gastala

Valerie Gilchrist

Rick Glazier

Stephanie Gold

English Gonzalez
Larry Green

Robert Hall

*Seneca Harberger

Sandra Hassink

Carolyn Hewson

Amanda Howe

Lauren Hughes

Elizabeth Hutchinson

Jane Ireland

Yalda Jabbarpour

Susan Jackson

Paul James

*Jonathan Jimenez

Lara Jirmanus

Samuel Jones

Douglas Kamerow

Art Kaufman

Christina Kelly

Ali Khan

Kristen Kimbrel

*Nathan Kittle

Kathleen Klink

Keith Knepp

Chris Koller

Stanley Kozakowski

Meredith Kratzmann

Alex Krist

Allana Krolikowski

Anton Kuzel

Lisa LeRoy

Lenny Lessor

Evelyn Lewis\&Clark

Winston Liaw

Kenneth Lin

Steven Lin

Kurt Lindberg

Jennifer Lochner

Theodore Long

*Elizabeth Looney

Daniel Lowenstein

Sean Lucan

Rebecca Luoh

Laura Makaroff

Marie Mann

Jason Marker

Paul Martin

*Sara Martin

Amy Matheny

Kristine McCoy

Lloyd Michener 
Benjamin Miller

Miranda Moore

Andrew Morris-Singer

Fitz Mullan

*Justin Mutter

Sharon Nabaka

Krishman Narasimhan

Marci Nielsen

Marc Nivet

Terri Nordin

Eleni O'Donovan

Nwando Olayiwola

Ann O'Malley

Kavita Patel

Lars Peterson

Bob Phillips

Russell Phillips

Claire Pomeroy

Maria Portela-Martinez

James Puffer

Casey Quinlan

Melanie Raffoul

*David Rebedew

Eugene Rich

Brad Richards
Diane Rittenhouse

*Max Romano

Dana Safran

Dave Schmitz

Laura Sessums

Manisha Sharma

*Alyssa Shell

Scott Shipman

Kurt Stange

Glen Stream

Erin Sullivan

Robyn Tamblyn

*Kenji Taylor

Sebastian Tong

Doug Tynan

Olga Valdman

Kara Walker

Jane Weida

Nicholas Weida

Thomas Weida

Therese Wetterman

Peter Wingrove

*Diana Wohler

Shale Wong

Julie Wood 